\title{
EFEITOS DE MEIOS DE CULTURA NA FORMAÇÃO DE CALOS A PARTIR DE ANTERAS DE ASPARGO (ASPARAGUS OFFICINALIS L.)
}

\author{
Vera Lucia Bobrowski ${ }^{1}$ \\ José Antônio Peters ${ }^{2}$ \\ Eliane Augustin ${ }^{3}$ \\ Judith Viégas ${ }^{4}$
}

Recebido em 04.08.93. Aceito em 23.03.95.

\begin{abstract}
RESUMO - Técnicas auxiliares, como a cultura de anteras, possibilitam melhor eficiência na obtenção de novos genótipos de aspargo. Neste trabalho, foram utilizadas anteras contendo grãos de pólen, no estágio uninucleado, dos híbridos 56×22-8 e 47×22-8, em meio MS, semi-sólido e líquido, com diferentes concentrações de reguladores de crescimento: meio $\mathrm{A}-0,5 \mathrm{mg} / \mathrm{BAP}+0,1$ $\mathrm{mg} / \mathrm{l} \mathrm{ANA}+0,5 \mathrm{mg} / \mathrm{l}$ 2,4-D + $20 \mathrm{~g} / \mathrm{l}$ sacarose $+20 \mathrm{~g} / \mathrm{l}$ glicose; meio B - 0,5 mg/l 2,4-D + $30 \mathrm{~g} / \mathrm{l}$ sacarose; meio C - 3,0 mg/l ANA + 0,5 mg/l Kin $+30 \mathrm{~g} / \mathrm{l}$ sacarose e meio D - 2,0 mg/l ANA + 0,5 $\mathrm{mg} / \mathrm{l} \mathrm{Kin}+30 \mathrm{~g} / \mathrm{l}$ sacarose. A formação de calos variou com o genótipo e o meio. Os meios líquidos apresentaram melhor eficiência na indução de calos do que os meios semi-sólidos. Para o híbrido $56 \times 22-8$ os melhores meios foram o $\mathrm{A}_{2}$ (líquido) com $80,5 \%$ de indução de calos e dentre os meios semi-sólidos, o meio $\mathrm{D}_{1}$ com $41,6 \%$ de calos formados. Para o híbrido $47 \times 22-8$, o mais eficiente foi o meio $\mathrm{D}_{2}$ (líquido), com $68,1 \%$ de calos formados e, dentre os meios semi-sólidos, o $\mathrm{D}_{2}$ com $15,2 \%$. Não ocorreram diferenças significativas, estatisticamente, entre os meios líquidos nem entre os meios semi-sólidos.
\end{abstract}

Palavras-chave: Cultura de anteras, haplóides, Asparagus officinalis L. Abreviaturas: BAPBenzilaminopurina; ANA-Ácido Naftalenoacético 2,4-D-Ácido 2,4-Diclorofenoxiacético; KinCinetina.

ABSTRACT - Anther culture is an auxiliary technique to obtain new genotypes. In this work,

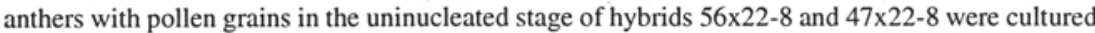
in MS medium, semi-solid and liquid, with different concentrations of growth regulators: medium A - $0,5 \mathrm{mg} / 1 \mathrm{BAP}+0,1 \mathrm{mg} / \mathrm{l} \mathrm{NAA}+0,5 \mathrm{mg} / 1$ 2,4-D $+20 \mathrm{~g} / \mathrm{l}$ sucrose $+20 \mathrm{~g} / \mathrm{l}$ glucose; medium B $-0,5 \mathrm{mg} / \mathrm{l}$ 2,4-D + $30 \mathrm{~g} / \mathrm{l}$ sucrose; medium $\mathrm{C}-3,0 \mathrm{mg} / \mathrm{l} \mathrm{NAA}+0,5 \mathrm{mg} / \mathrm{l} \mathrm{Kin}+30 \mathrm{~g} / \mathrm{l}$ sucrose and medium D - 2,0 mg/l NAA $+0,5 \mathrm{mg} / \mathrm{l} \mathrm{Kin}+30 \mathrm{~g} / \mathrm{l}$ sucrose. Callus formation varied with the

\footnotetext{
${ }^{1}$ Departamento de Genética, Instituto de Biologia, UFPel, Cx. P. 354, Pelotas/RS.

2 Departamento de Botânica, Instituto de Biologia, UFPel, Cx. P.354, Pelotas/RS, bolsista CNPq.

${ }^{3}$ EMBRAPA/CPACT, Cx. P. 403, Pelotas/RS, bolsista CNPq.

${ }^{4}$ Bolsista DTI/RHAE, Lab. Biologia Celular CPACT/UFPel, Cx. P. 403,Pelotas/RS.
} 
genotype and the medium. Liquid media showed more efficiency in callus development than the semi-solids. For the hybrids $56 \times 22-8$ the best media were the liquid $\mathrm{A}_{2}$ with $80,5 \%$ of callus induction and among the semi-solids the $\mathrm{D}_{1}$ with $41,6 \%$. For the hybrid $47 \times 22-8$ were liquid $\mathrm{D}_{2}$ with $68,1 \%$ and semi solid $D_{1}$ with $15,2 \%$. No significant differences were observed among the liquid media nor among the semi-solidones.

Key words: Anther culture, haploids, Asparagus officinalis L.

\section{Introdução}

A eficiência dos programas de melhoramento do aspargo é reduzida em virtude de sua natureza perene e dióica e da baixa taxa de multiplicação vegetativa (Augustin et al.,1990).

A cultura de tecidos tornou-se, portanto, uma ferramenta importante no auxílio ao melhoramento convencional desta espécie. Dentre as diversas técnicas disponíveis, a cultura de anteras tem-se mostrado valiosa, pois, além de facilitar a análise genética, possibilita a expressão de mutações e permite a diminuição do tempo necessário para a obtenção de uma linha pura (Moraes-Fernandes, 1990). O principal objetivo técnico com aspargo é a obtenção de haplóides masculinos para, por duplicação cromossômica, obter plantas diplóides homozigotas. Estas são de grande interesse pois permitem obter, em um intervalo de tempo menor do que o de processos convencionais, novos cultivares com probabilidade de maior produtividade. Através do melhoramento convencional, a obtenção de plantas masculinas, homozigotas dominantes para o caráter sexo (YY), só poderiam ser obtidas partindo-se de plantas andromonóicas (com flores masculinas e hermafroditas na mesma planta) e selecionando a sua descendência. Considerando-se a baixa ocorrência, na natureza, destas plantas (inferior a $2 \%$ ), este processo se torna demasiado longo e por vezes infrutífero. O sucesso na produção de plantas haplóides, via cultura de anteras, requer a adaptação das técnicas androgenéticas, de acordo com as diferenças entre genótipos (Augustin et al 1990).

Três pontos são de fundamental importância na obtenção de plantas através da cultura de anteras do aspargo: (1) formação de calos a partir de anteras; (2) formação de gemas a partir de calos e (3) obtenção de plantas a partir destas gemas (Doré, 1973; Inagaki et al.,1981, Falavigna et al.,1990; Romeau, 1990). A primeira etapa neste processo é a obtenção de calos. São vários os fatores que afetam diretamente este processo: o genótipo, o estágio fisiológico da planta doadora de anteras, o estágio de desenvolvimento do grão de pólen e o meio de cultura (Nitsch,1981; Doods \& Roberts,1982; Dunwell,1985). Há uma diversidade de resposta de determinados genótipos na indução de calos dependendo do meio de cultivo utilizado (Falavigna et al.,1990). Neste trabalho testaram-se diferentes composições de meios para obtenção de uma maior eficiência de indução de calos para os híbridos $47 \times 22-8$ e 56x22-8, produzidos pela EMBRAPA-CPACT, os quais são bem adaptados às condições edafoclimáticas da região e apresentam boa produtividade. 


\section{Materiais e métodos}

Foram utilizadas anteras de dois híbridos (47×22-8 e 56×22-8) cultivados em casa de vegetação.

A fim de correlacionar tamanho do botão floral com o estágio de desenvolvimento do grão de pólen, foi medido o comprimento floral e foi verificada a coloração do mesmo e analisada a posição do núcleo, na maioria dos grãos de pólen de cada botão. Os botões florais foram separados em quatro classes, em função do tamanho: 0,5 - 1,0; 1,1 - 1,5; 1,6 - 2,0 e maiores que 2,1 $\mathrm{mm}$, sendo analisados 25 botões em cada classe. As anteras foram retiradas, colocadas sobre uma lâmina e esmagadas com um bastão de vidro para liberação dos grãos de pólen. O material foi corado com carmim acético $1 \%$. Com o auxílio de microscópio óptico, fez-se a determinação dos diferentes estágios de desenvolvimento dos grãos de pólen, considerando principalmente a posição do núcleo deslocado para um dos polos da célula, como característica do estágio uninucleado.

Para a cultura in vitro, botões florais contendo anteras com grãos de polén no estágio uninucleado foram desinfestados por imersão em álcool $70 \%$ por 3 segundos e, após, em solução de hipoclorito de cálcio $1 \%$ por 10 minutos. A seguir, o material foi lavado três vezes em água destilada esterilizada, permanecendo nesta até transferência para o meio de cultura. Todos os procedimentos de desinfestação foram realizados em câmara asséptica de fluxo laminar.

O meio mineral básico utilizado para a formação de calos foi o MS (Murashige \& Skoog, 1962) com modificações quanto a parte vitamínica (tiamina- $\mathrm{HCl}$, piridoxina, glicina, ácido nicotínico e biotina a $1,0 \mathrm{mg} / \mathrm{l}$ de cada uma). Ao meio mineral básico foram adicionados $100 \mathrm{mg} / \mathrm{l}$ de mio-inositol, diferentes combinações de sacarose e/ou glicose e reguladores de crescimento (BAP, ANA, 2,4-D e Kin), compondo quatro meios: Meio A - MS + 0,5 mg/l BAP + 0,5 mg/l 2,4-D + 0,1 mg/l ANA + $20 \mathrm{~g} / \mathrm{l}$ sacarose $+20 \mathrm{~g} / \mathrm{l}$ glicose

Meio B - MS + 0,5 mg/l 2,4-D + $30 \mathrm{~g} / \mathrm{l}$ sacarose

Meio C $-\mathrm{MS}+3,0 \mathrm{mg} / \mathrm{l} \mathrm{ANA}+0,5 \mathrm{mg} / \mathrm{l} \mathrm{Kin}+30 \mathrm{~g} / \mathrm{l} \mathrm{sacarose}$

Meio D - MS + 2,0 mg/l ANA + 0,5 mg/l Kin $+30 \mathrm{~g} / \mathrm{l}$ sacarose

Os quatro meios foram usados em dois estados físicos, semi-sólido $\left(\mathrm{A}_{1}\right.$ a $\left.\mathrm{D}_{1}\right)$, e líquido $\left(\mathrm{A}_{2} \mathrm{a} \mathrm{D}_{2}\right)$. Aos meios semi-sólidos foram adicionadas $6 \mathrm{~g} / \mathrm{l}$ de agar, após ajuste do $\mathrm{pH}(5,8)$.

Foram utilizados $40 \mathrm{ml}$ de meio por frasco de $200 \mathrm{ml}$ de volume e esterilizados por $15 \mathrm{~min}$ a $121 \pm 1^{\circ} \mathrm{C}$ e 1,5 atm de pressão. Os meios semi-sólidos foram denomina$\operatorname{dos} \mathrm{A}_{1}, \mathrm{~B}_{1}, \mathrm{C}_{1}$ e $\mathrm{D}_{1}$ e os meios líquidos de $\mathrm{A}_{2}, \mathrm{~B}_{2}, \mathrm{C}_{2}$ e $\mathrm{D}_{2}$.

As anteras, inoculadas nos diferentes meios, foram mantidas no escuro, em câmara de crescimento, à temperatura de $27 \pm 1^{\circ} \mathrm{C}$ por 30 dias. Ao final, verificou-se para cada genótipo o número de calos formados e observou-se o aspecto dos mesmos.

O experimento conduzido foi um fatorial, com dois fatores (meios e genótipos) num delineamento inteiramente casualizado com três repetições. A unidade experimental foi o frasco com o meio de cultivo, cada um contendo 24 anteras de cada 
genótipo. Para complementar os resultados da análise de variância, utilizou-se o teste de Duncan a $5 \%$ para a variável, número de calos por frasco (devidamente transformada segundo raiz quadrada de $\mathrm{x}$ ).

\section{Resultados e discussão}

Verificou-se que botões florais medindo 1,6 a 2,0 mm de comprimento, apresentavam a maioria dos grãos de pólen no estágio uninucleado (Tabela 1). Estes botões possuem anteras de coloração verde amarelada, sendo esta outra característica que pode ser utilizada para a escolha do material a ser colocado in vitro. A Figura 1 apresenta, citologicamente, estágios de desenvolvimento dos grãos de pólen, para as quatros classes de botões florais estudadas, mostrando que pequenas variações no comprimento dos mesmos, determinam diferenças no estágio de desenvolvimento dos grãos de pólen.
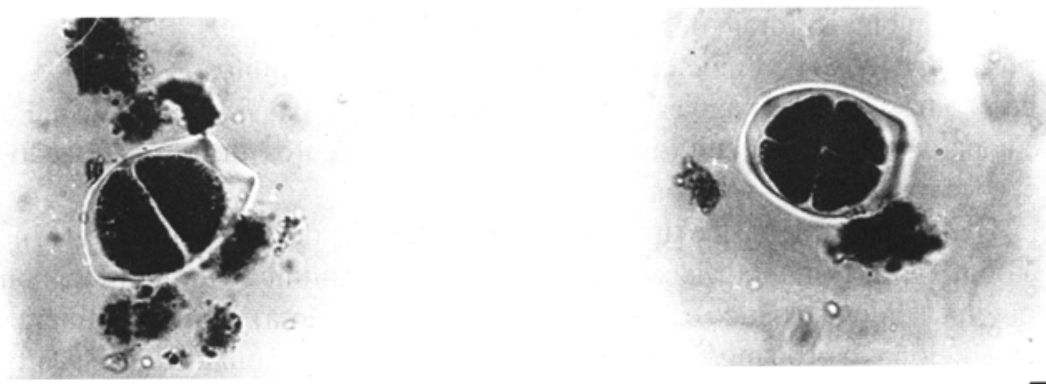

A

B
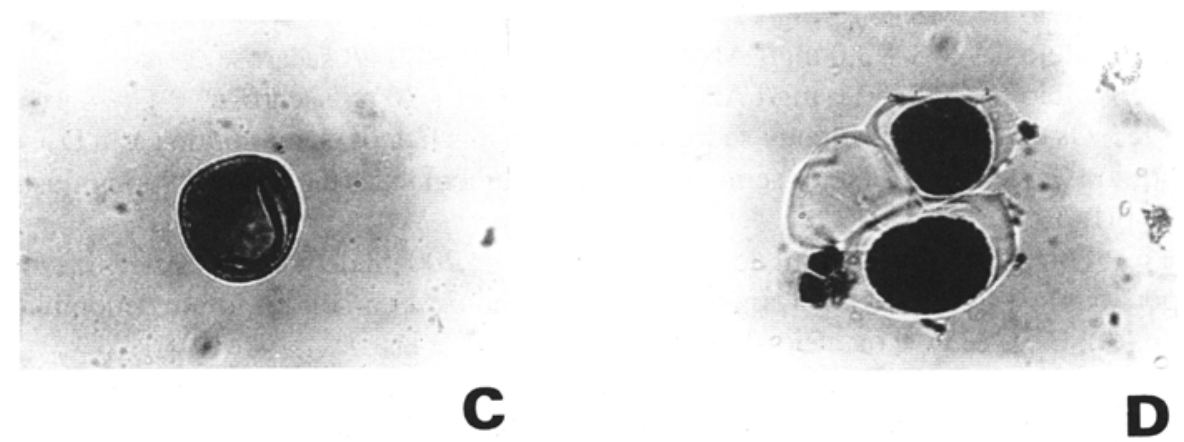

D

Figura 1. Diferentes estágios de desenvolvimento dos grãos de pólen de acordo com o comprimento do botão floral. (A) Díade, (0,5 a 1,0 mm); (B) Tétrade (1,0 a 1,5 mm); (C) Pólen uninucleado (1,5 a 2,0 mm); (D) Pólen maduro ( $>2,0 \mathrm{~mm})$. 
Tabela 1. Correlação entre tamanho de botão floral, coloração das anteras e estágio de desenvolvimento do grão de pólen em aspargo.

\begin{tabular}{cll}
\hline Tamanho do botão & $\begin{array}{l}\text { Coloração das } \\
\text { anteras }\end{array}$ & $\begin{array}{l}\text { Estágio de desenvolvimento floral (mm) } \\
\text { do grão de pólen }\end{array}$ \\
\hline 0,5 a 1,0 & branca & díade \\
1,1 a 1,5 & verde & tétrade \\
1,6 a 2,0 & verde-amarelada & pólen uninucleado \\
$>2,1$ & amarela & pólen maduro \\
\hline
\end{tabular}

Para a realização deste trabalho, foram utilizados somente botões florais medindo entre 1,6 a 2,0 $\mathrm{mm}$ de comprimento, contendo anteras verde-amareladas, pois segundo Pelletier et al. (1972) e Doré (1974), no aspargo, o estágio uninucleado é indicado como aquele no qual se obtem maior divisão celular dos grãos de pólen e formação de calos.

A análise de variância do número de calos formados a partir de anteras dos híbridos 56×22-8 e 47×22-8, nos oito meios de cultura, mostrou diferenças significativas entre genótipos, entre meios de cultura e na interação genótipo x meio de cultura (Tabela 2).

Tabela 2 - Número médio de calos/frasco, para os híbridos 56×22-8 e 47×22-8 em diferentes meios de cultura.

\begin{tabular}{|c|c|c|c|}
\hline \multicolumn{2}{|c|}{ Meio de indução } & \multicolumn{2}{|c|}{ Número médio de calos/frasco } \\
\hline Estado físico & Tipo & $56 \times 22-8$ & $47 \times 22-8$ \\
\hline \multirow[t]{4}{*}{ Semi-sólido } & $\mathrm{A}_{1}$ & $5,6 \mathrm{~d} \quad \mathrm{~A}$ & $1,9 \mathrm{~b} \quad \mathrm{~B}$ \\
\hline & $\mathrm{B}_{1}$ & $8,6 \mathrm{c}$ & $1,9 \mathrm{~b} \quad \mathrm{~B}$ \\
\hline & $\mathrm{C}_{1}$ & $5,3 \mathrm{~d} \quad \mathrm{~A}$ & $2,9 \mathrm{~b} \quad \mathrm{~B}$ \\
\hline & $\mathrm{D}_{1}$ & $9,9 \mathrm{c} \quad \mathrm{A}$ & $3,5 \mathrm{~b} \quad \mathrm{~B}$ \\
\hline \multirow[t]{4}{*}{ Líquido } & $\mathrm{A}_{2}$ & 19,3 a $A$ & 13,1 a $\mathrm{B}$ \\
\hline & $\mathrm{B}_{2}^{-}$ & $14,3 \mathrm{~b} \quad \mathrm{~A}$ & 16,2 a $\mathrm{A}$ \\
\hline & $\mathrm{C}_{2}^{2}$ & 14,9 ab $\mathrm{A}$ & 13,1 a $\mathrm{A}$ \\
\hline & $\mathrm{D}_{2}$ & $16,3 \mathrm{ab} A$ & 15,6 a A \\
\hline
\end{tabular}

* Médias seguidas pela mesma letra maiúscula, nas linhas, e pela mesma letra minúscula, nas colunas, não diferem entre si, pelo teste de Duncan, ao nível de probabilidade de 5\%.

O híbrido 56×22-8 apresentou resultados mais favoráveis que o $47 \times 22-8$ quando utilizados os meios $A_{1}, B_{1}, C_{1}$ e $D_{1}$ e $A_{2}$, não sendo a diferença significativa 
entre os demais meios. Esta variação da resposta androgenética que se observa entre os híbridos foi também verificada por Quiao \& Falavigna (1990), que encontraram variações na frequência da resposta das anteras a um determinado meio, de acordo com o genótipo da planta doadora.

Para o híbrido 56×22-8, os meios em que se obtiveram melhores respostas foram $\mathrm{A}_{2}, \mathrm{D}_{2}$ e $\mathrm{C}_{2}$ com médias de 19,3; 16,3 e 14,9 calos/frasco, respectivamente, não diferindo significativamente entre si. Dentre os meios semi-sólidos o meio $\mathrm{D}_{1}$ com média de 9,9 calos/frasco e o meio $\mathrm{B}_{1}$, com média de 8,6 calos/frasco foram os melhores, não diferindo significativamente entre si.

Assim como para o híbrido 56×22-8, os meios líquidos foram mais favoráveis que os semi-sólidos para o híbrido $47 \times 22-8$, sendo que os melhores meios foram $\mathrm{B}_{2}$, $\mathrm{D}_{2}, \mathrm{C}_{2}$ e $\mathrm{A}_{2}$ (todos líquidos e não diferindo estatisticamente entre si) com médias de 16,$2 ; 15,6 ; 13,3$ e 13,3 calos/frasco, respectivamente. No entanto, observou-se que, qualitativamente, os calos produzidos no meio $\mathrm{B}_{2}$ eram menores que os demais e oxidavam facilmente. Entre os meios semi-sólidos, os meios $\mathrm{D}_{1}, \mathrm{C}_{1}, \mathrm{~B}_{1}$ e $\mathrm{A}_{1}$ não diferiram estatisticamente entre si,e apresentaram respectivamente médias de 3,5; 2,9; 1,9 e 1,9 calos/frasco. Estes resultados, onde os meios líquidos são superiores aos semi-sólidos, estão em concordância com os obtidos por Dunwell (1985), para aspargo. Em cevada, Marsolais \& Kasha (1985) também verificaram que uma alta produção de calos era obtida em meios líquidos.

A utilização do meio $\mathrm{A}_{1}$ para indução de calos, apresentou resultados semelhantes aos obtidos por outros autores. Doré (1973) obteve um percentual de indução de calos de $8 \%$. Quiao \& Falavigna (1990) encontraram uma frequência que variou de 0,7 a $12,8 \%$, conforme a cultivar utilizada. O percentual de $8,3 \%$ (1,9 calos/frasco) de formação de calos obtido com o híbrido 47x22-8 está próximo ao observado por estes autores. O percentual obtido com o híbrido $56 \times 22-8$, entretanto, foi superior $(23,6 \%$ ou 5,6 calos/frasco). Quando utilizado este meio no estado líquido (meio $\mathrm{A}_{2}$ ), a inducão foi mais eficiente que a obtida em meio semi-sólido, sendo de 55,5 (13,3 calos/frasco) e 80,5\% (19,3 calos/frasco), respectivamente para os genótipos $47 \times 22$ 8 e $56 \times 22-8$.

As frequências de indução de calos para os meios $\mathrm{C}_{1} \mathrm{e} \mathrm{D}_{1}$, foram menores que as obtidos por Bin et al. (1989) utilizando meio de cultivo semelhante, porém com concentrações de ANA e Kin mais elevadas. Estes autores, utilizando meio com 5,0 mg/l ANA $+1,0$ mg/l Kin, para cv. Mary Washington, obtiveram 74,4\% de formação de calos. Por outro lado, os meios líquidos $\mathrm{C}_{2}$ e $\mathrm{D}_{2}$ apresentaram bons índices de formação de calos,ou seja, 14,9 e 16,3 calos/frasco para o híbrido 56x22-8 e 13,1 e 15,6 para o híbrido $47 \times 22-8$, respectivamente.

Os calos formados após a abertura da antera apresentavam-se de coloração esbranquiçada e com consistência compacta, tornando-se mais friáveis conforme o crescimento, tanto em meio semi-sólido como líquido. (Figura 2) 


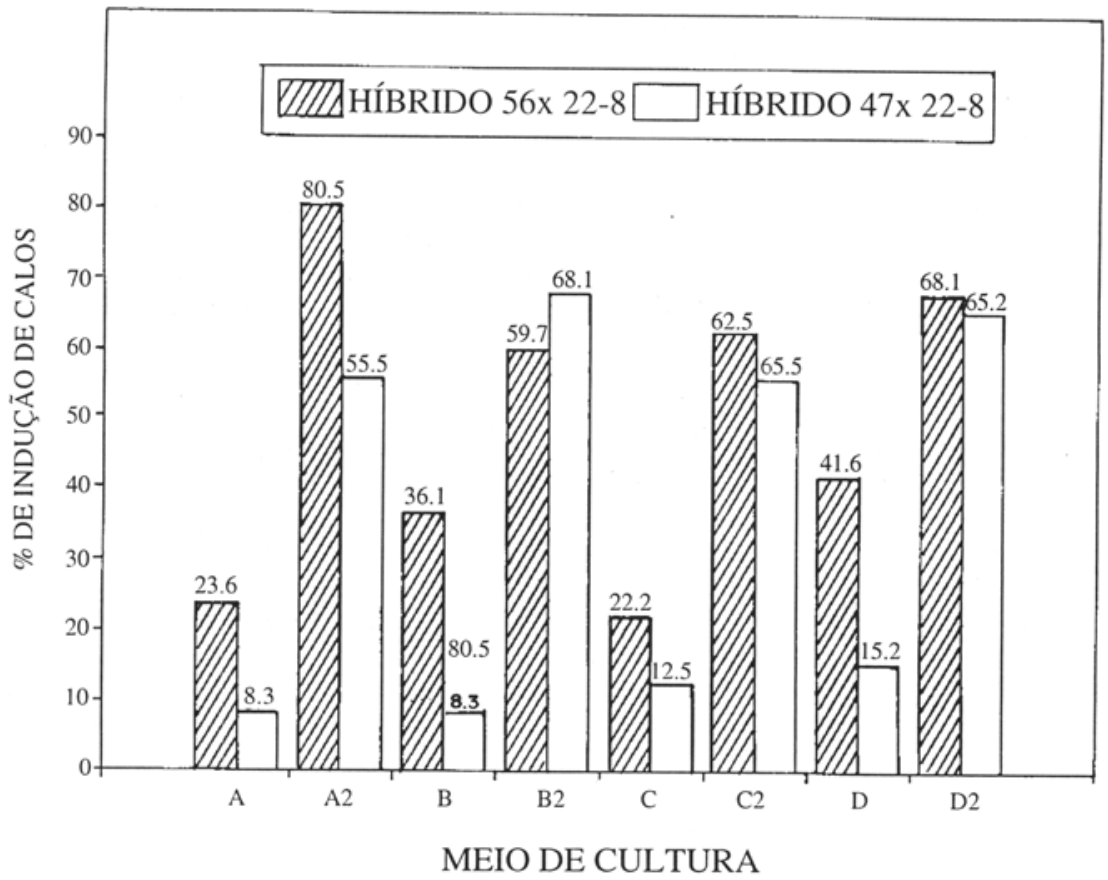

Figura 2. Calo formado a partir de antera do aspargo, híbrido 47×22-8. A escala equivale a $5 \mathrm{~mm}$.

\section{Conclusões}

Botões florais com 1,6 a 2,0 mm de comprimento apresentaram a maioria dos grãos de pólen no estágio uninucleado. O melhor meio de cultura para indução de calos variou comforme o genótipo, $\mathrm{A}_{2}$ para o híbrido $56 \times 22-8$ e $\mathrm{D}_{2}$ para o $47 \times 22-8$, sendo os meios líquidos mais eficientes que os meios semi-sólidos.

\section{Referências bibliográficas}

Augustin, E., Moraes, E.C., Osório, V. A., Couto, M. E. O., Peters, J.A., Salles, L. A. B. 1990. A Cultura do Aspargo, Pelotas, EMBRAPA- CNPFT (Circular Técnica, n.15).

Bin, Z., Ming, W., Ni-Yun, H. 1989. Studies on the anther culture of asparagus. In VII International Asparagus Symposium. Ferrara, Italia, 1989. Abstracts, Ferrara, p.10.

Doods, J. H. \& Roberts, L. W. 1982. Anther and Pollen Cultures. In Doods, J. H. and Roberts, L. W. Experiments in tissue culture, Cambridge University Press, p.127-140.

Doré, C. 1973. Androgenese in vitro par culture d' antheres d'Asparagus officinalis. I. Etat Atuel des Recherches. Eucarpia 1:173-182.

Doré, C. 1974.Production de plantes homozigotes mâles et femelles à partir d'antheres cultivées (Asparagus officinalis L.). C.R. Acad. Sc. Paris 278:2135-2138.

Dunwell, J.M. 1985. Haploid cell culture. In DIXON, R.A., Plant cell culture, a pratical approach. Oxford, IRL Press Limited, p.21-37. 
Falavigna, A., Casali, P.E., Taconi, M.G. 1990. Potencial of in vitro anther culture technique for asparagus breeding in Italy. Acta Horticulture, 271:39-54.

Inagaki, N., Harada, T., Yakuma, T. 1981. Studies on anther culture of horticultural crops. IV. Regeneration on plantlets from shoots obtained through the anther culture of Asparagus officinalis L. J. Fac. Agron. Hokkaido Univ., 60:275-283.

Marsolais, A. A. \& Kasha, K. J. 1985. Callus induction from barley microspores. The role of sucrose and auxin in barley anther culture medium. Can. J. Bot., 63:2209-2212.

Morais-Fernandes, M. I. B. 1990. Obtenção de plantas haplóides através da cultura de anteras. In TORRES, A. C. Técnicas e Aplicações da Cultura de Tecidos de Plantas. Brasília: ABCTP/ EMBRAPA, p.311-332.

Murashige, T. \& Skoog, F.1962. A revised medium for rapid growth and bioassay with tabaco tissue cultures. Physiol. Plant., 15:473-497.

Nitsch, C. 1981. Production of isogenic lines: basic technical aspects of androgenesis. In THORPE, T.A., Plant Tissue Culture, Methods and Applications in Agriculture, New York: Academic Press. p.24122450 .

Quiao, Y. M. \& Falavigna, A. 1990. An improved in vitro anther culture method for obtaing doubledhaploid clones of asparagus. Acta Horticulture, 271:145-154.

Pelletier, G., Raquin, C., Simon, G. 1972. Histophysiologie végetal. La culture in vitro d'anther (Asparagus officinalis L.).C. R. Acad. Sc. Paris., 274: 848-851.

Romeau, C. 1990. Fifteen years of experiments on asparagus F1 hibryds: synthesis, evaluation of homozygous parents and applications to the french breeding programme. Acta Horticulture, 271:5562. 